\title{
The perception of strabismus by children and adults
}

\author{
Stefania Margherita Mojon-Azzi • Andrea Kunz • \\ Daniel Stéphane Mojon
}

Received: 26 May 2010/Revised: 19 October 2010 /Accepted: 21 October 2010 /Published online: 10 November 2010

(C) Springer-Verlag 2010

\begin{abstract}
Background Visible strabismus has been shown to have adverse psychosocial consequences. It remains controversial if esotropia or exotropia is perceived more negatively. The aim of this study was to determine if esotropia or exotropia and the eye (side) in which strabismus is present are perceived differently. We also asked our adult participants: (1) if they thought visible strabismus should be corrected by surgery, (2) if they thought that strabismus surgery should only be to improve the cosmesis, and (3) if they thought that the surgery should be paid for by health insurance.

Methods One hundred adults and 61 children rated four photographs of a digitally altered picture of a boy and four of a girl, showing a large-angle esotropia or exotropia either in the left or on the right eye. The adults were additionally asked if a squint should be operated, if they considered strabismus surgery to be a cosmetic procedure, if in their opinion strabismus surgery should be covered by compulsory health
\end{abstract}

The authors have no financial interest in the topic of this article.

\section{Grants/financial supports None}

S. M. Mojon-Azzi

Research Institute for Labour Economics and Labour Law, University of St. Gallen,

St. Gallen, Switzerland

A. Kunz $\cdot$ D. S. Mojon $(\bowtie)$

Department of Strabismology and Neuro-Ophthalmology,

Kantonsspital St. Gallen,

St. Gallen 9007, Switzerland

e-mail: daniel.mojon@kssg.ch

D. S. Mojon

University of Bern,

Bern, Switzerland insurance, and if children with strabismus are disadvantaged. Comparisons were performed using ANOVA and regression analysis.

Results Adults perceived a squinting right eye as more disturbing than a squinting left eye $p<0.001$ ). The direction of strabismus, the age, gender, and the number of persons with a squint among family and friends of the respondents did not influence the perception of strabismus by adults $(p>0.1$ for each). Children also found that a squinting right eye is more disturbing $(p<0.001)$ than a left one. Additionally, children ranked esotropia worse than exotropia $(p<0.001)$. Neither age nor gender had an impact on the perception of strabismus by children. Of the adults, 94\% would recommend surgery for all forms of strabismus, $18 \%$ thought that surgery is only cosmetic, and $94 \%$ found that health insurance should cover strabismus surgery for everybody. Problems of squinting children named by the adults included: being made fun of by other children (53\%), problems with eyesight (39\%), people looking strangely at them (21\%), less acceptance by peers $(17 \%)$, less self confidence $(6 \%)$, problems judging distances $(4 \%)$, and that they are perceived as less intelligent (3\%).

Conclusions Adults and children rated a squinting right eye as worse compared to a left one. Children perceived esotropia as more disturbing than exotropia. Neither age, nor gender, nor the fact that the respondents have friends or family members with a squint, had an impact on this ranking. Almost all adults would correct all forms of strabismus, and think that surgery should be covered by compulsory health insurance.

Keywords Strabismus $\cdot$ Exotropia $\cdot$ Esotropia $\cdot$ Psychosocial aspects 


\section{Introduction}

Strabismus is a visible facial abnormality that has been shown to have adverse psychosocial consequences in adults $[2,3,8-11]$ and children $[12,15]$.

With regard to the differences in the perception of esotropia and exotropia, several studies have come to contradictory conclusions.

Johns et al. [6] evaluated the effect of strabismus on the selection of playmates by children, and found that almost equal percentages of exotropic and esotropic children were selected as playmates. Paysse et al. [12] studied the behavior of children aged between 3 and 7 years toward orthotropic, esotropic, and exotropic dolls. The three dolls were the only toys with which to play and placed in a waiting room. The children were observed through a oneway mirror, and also interviewed afterwards with standardized questions. The study found that a negative attitude toward strabismus emerges around the age of 6 years of age. Children aged 5 and three quarter years and older showed a tendency toward more negative behaviors towards the esotropic compared to the exotropic dolls. Such behaviors include throwing, striking, and verbally disparaging a doll. Because of the small number of subjects, separate analysis for orthotropic, esotropic and exotropic dolls could not be performed.

Uretmen et al. [15] analyzed the perception of children with strabismus by elementary school teachers, and found a negative social bias on the part of teachers against children with a squint. The children were rated more positively in the exotropic photographs than in the esotropic photographs for the characteristics hard work and happiness. Esotropic children were also perceived as having more difficulty in learning than exotropic children.

Olitsky et al. [11] found a negative impact of strabismus in adults. In their study, college students judged the effect of esotropia as worse than that of exotropia.

Coats et al. [2] showed that strabismus negatively influences a female applicant's ability to obtain employment, but displayed no significant differences between esotropia and exotropia.

In their analysis of the effect of strabismus on the rating of official US Army photographs of men and women in uniforms by military officers, Goff et al. [3] demonstrated that esotropic persons were rated significantly less favourably than orthotropic and exotropic ones.

In a study on the impact of strabismus on potential partners [10], dating agents judged that strabismic subjects have more difficulties than orthotropic ones in finding a partner, and that these difficulties are greater in exotropic than in esotropic persons. These results were confirmed by a study of the perception of squinting persons by potential employers [9], where headhunters judged that exotropic individuals would have more difficulties in finding an employment than esotropic ones.

Based on the contradictory results of previous studies and on the fact that, to the best of our knowledge, only the direction of strabismus but not the eye with strabismus were analysed, we tried to determine in children and adults which type of strabismus, exotropia or esotropia, on which eye, right or left, is perceived as worse. We also tried to find out if our adult participants think that visible strabismus should be corrected by surgery, if surgery should only be to improve the cosmesis, and if strabismus surgery should be paid for by health insurance.

\section{Materials and methods}

This study was approved by the Ethics Commission of the canton of St Gallen, and was performed in accordance with the ethical standards laid down in the 1964 Declaration of Helsinki. Written informed consent was obtained from all parents of the participating children and all adult subjects. The parents of the children shown on the photographs also gave written informed consent. One hundred adults and 61 children aged 6 to 11 years were each shown four photographs of the face of a boy and four photographs of the face of a girl. The four photographs were digitally altered, and differed only in the position of the eyes: esotropia or exotropia on the left or on the right eye (Fig. 1). The esotropic and exotropic eyes were obtained by digitally altering the original pictures with Adobe Photoshop 6.0 by using the techniques of merging and erasing. The squint angles corresponded to 50 prism diopters. These angles were used in the majority of previous studies $[2,9$ 11]. The participants were asked to rank the four photographs of the boy and the four of the girl from the one where the squint is most bothering (rank 1) to the one where it bothers least (rank 4). All eight photographs were shown at the same time. The 100 adults were then asked if they thought a squint should be operated, if they considered strabismus surgery to be only a cosmetic procedure or not, and if in their opinion strabismus surgery should be covered by compulsory health insurance or not. Finally the adults were asked if they thought that children with strabismus are somehow disadvantaged, and if yes, which are the possible disadvantages.

All participants attended the Department of Ophthalmology at Kantonsspital St Gallen or accompanied a child there. Subjects with physical impairments or not speaking German were excluded.

In order to determine if the four represented forms of strabismus ranked significantly differently for each age group, a one-way between-groups ANOVA was performed. 

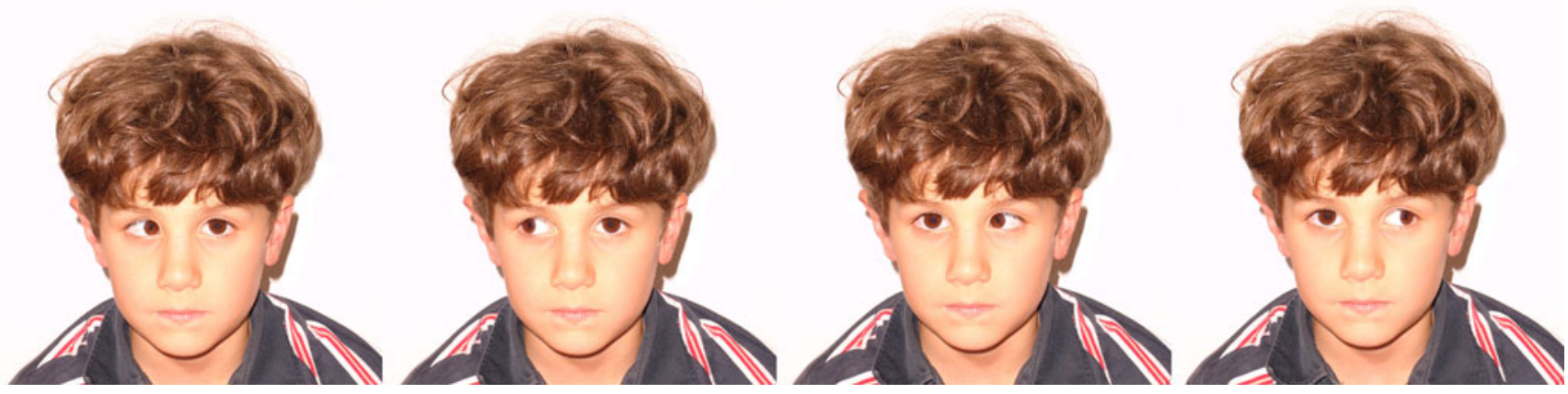

Fig. 1 Photographs of the boy shown for rating. From left to right: right esotropia, right exotropia, left esotropia, left exotropia

To evaluate if the direction of strabismus (esotropia and exotropia) or the affected eye (right or left) had an impact on the ranking, separate regression analyses for adults and children were performed, using age, gender, and the number of persons with a squint among family and friends as covariates.

Finally, logistic regressions were performed to evaluate if age, gender or the number of persons with a squint in the family and among friends have an impact on the opinion as to whether strabismus surgery should be performed, whether it should be covered by health insurance, and whether it is only a cosmetic procedure or not.

Differences were accepted as significant at the $p<0.05$ level.

All statistics were performed with R Version 2.9.1.

\section{Results}

Sixty-one children (31 girls and 30 boys) aged 6 to 11 (mean 8.4, SD 1.4) and 100 adults ( 75 women and 25 men) aged 16 to 83 (mean 38.6, SD 13.0) were asked to rank the four pictures of the boy and the four of the girl from the most (rank 1) to the least disturbing (rank 4). None of the children and $36 \%$ of the adults had squinting persons in the family or among their close connections. The results of this ranking are displayed in Table 1 and Fig. 2.

For most age groups, the results of the one-way between-group ANOVAs displayed significant differences in the ranking of the four represented groups (Table 1).

Regression analysis for adults respondents showed a highly significant impact of the eye $(p<0.001)$ on the ranking, where the right eye was perceived as more disturbing than the left eye. The direction of strabismus, the age, gender, and the number of persons with a squint among family and friends of the respondents had no significant impact on the rank.

Regression analysis for children only confirmed the results of the adults, in that a squinting right eye was perceived as more disturbing $(p<0.001)$ than a left one.
Additionally, children ranked esotropia as highly significantly $(p<0.001)$ worse than exotropia. Neither age nor gender had an impact on the perception of strabismus by children.

The logistic regressions showed no impact of age, gender or the number of persons with a squint in the family $(p>0.1)$ on the opinion as to whether strabismus surgery should be performed, whether it should be covered by health insurance, and whether surgery is only a cosmetic procedure or not.

Out of the 100 interviewed adults, three persons (95\% CI $1.1 \%-8.4 \%$ ) would not operate on the children with a squint, three (95\% CI $1.1 \%-8.4 \%)$ would perform surgery only in some of the pictured children, and the remaining 94 (95\% CI 87.5\%-97.2\%) would recommend correcting all forms of strabismus with a surgical intervention.

Out of 100 adult respondents, 18 persons (95\% CI $11.7 \%-27.0 \%$ ) thought that the surgical intervention is only a cosmetic procedure, $13(95 \%$ CI $7.8 \%-21.0 \%)$ said that this should be decided by a specialist, and $69(95 \% \mathrm{CI}$ $59.3 \%-77.4 \%$ ) found that strabismus surgery is not only cosmetic but would enhance visual functions.

Out of the 100 interviewed persons, one person $(95 \% \mathrm{CI}$ $0 \%-5.4 \%$ ) said that strabismus surgery should not be covered by compulsory health insurance, five persons (95\% CI 2.2\%-11.2\%) thought that it should be covered for children but not for adults, and the remaining 94 persons (95\% CI 87.5\%-97.2\%) stated that health insurance should cover strabismus surgery for everybody.

Asked about possible problems children with strabismus are confronted by, ten respondents (95\% CI 5.6\%-17.5\%) answered "none", 53 (95\% CI 43.3\%-62.5\%) feared that squinting children are made fun of by other children, 17 (95\% CI $10.9 \%-25.6 \%)$ that they are less accepted by peers, 21 (95\% CI 14.2\%-30.0\%) that people would look strangely at them, six (95\% CI 2.8\%-12.5\%) thought that children with a squint are less self-confident, $39(95 \% \mathrm{CI}$ $30.0 \%-48.4 \%$ ) said that they could have problems with their eyesight, four (95\% CI 1.6\%-9.8\%) feared they might have problems judging distances, e.g., playing with balls, 
Table 1 Ranking of strabismus (from $1=$ most disturbing to 4 = least disturbing) and results of the ANOVAs

$$
\text { Right ET mean rank (SD) Right XT mean rank (SD) } \quad \text { Left ET mean rank (SD) } \quad \text { Left XT mean rank (SD) } N \quad \begin{array}{llll}
N & \text { F }
\end{array}
$$

\begin{tabular}{|c|c|c|c|c|c|c|c|}
\hline All children & $2.2(0.9)$ & $2.4(0.9)$ & $2.4(0.8)$ & $3.1(0.8)$ & 61 & 14.7 & $<0.001$ \\
\hline All adults & $2.3(1.0)$ & $2.2(0.9)$ & $2.8(0.8)$ & $2.7(0.9)$ & 100 & 10.8 & $<0.001$ \\
\hline 6 to 7 years & $1.9(0.8)$ & $2.6(0.8)$ & $2.2(0.7)$ & $3.3(0.8)$ & 24 & 13.8 & $<0.001$ \\
\hline 8 to 9 years & $2.3(0.9)$ & $2.4(0.9)$ & $2.4(0.7)$ & $2.9(0.7)$ & 23 & 2.9 & 0.04 \\
\hline 10 to 11 years & $2.5(0.7)$ & $2.0(0.8)$ & $2.5(0.8)$ & $3.0(0.8)$ & 14 & 3.3 & 0.03 \\
\hline 16 to 30 years & $2.8(0.8)$ & $1.9(0.8)$ & $2.9(0.8)$ & $2.4(0.9)$ & 28 & 8.2 & $<0.001$ \\
\hline 31 to 40 years & $2.3(0.9)$ & $2.2(0.9)$ & $2.8(0.8)$ & $2.7(0.8)$ & 35 & 4.1 & 0.008 \\
\hline 41 to 50 years & $2.2(1.0)$ & $2.4(0.7)$ & $2.7(0.7)$ & $2.7(0.9)$ & 21 & 1.9 & 0.14 \\
\hline 51 to 83 years & $1.7(0.9)$ & $2.5(0.9)$ & $2.6(0.9)$ & $3.2(0.9)$ & 16 & 8.9 & $<0.001$ \\
\hline
\end{tabular}

and three $(95 \%$ CI $1.1 \%-8.4 \%)$ that they are perceived as less intelligent.

\section{Discussion}

Based on the opinion of 61 children and 100 adults, this study analyzed the perception of exotropia and esotropia in the left or the right eye in photographs showing a boy and a girl. The results show that both forms of strabismus are ranked similarly by adults, but a squinting right eye is ranked worse than a squinting left eye. Neither age, nor gender, nor the fact that the respondents have friends or family members with a squint, had an impact on this ranking. Our results confirm the study of Coats et al. [2], who found that the direction of the squint had no influence on the ability to obtain employment. However, other studies showed that that the direction of the squint matters. College students rated esotropia worse than exotropia [11], while dating agents [10] and headhunters [9] judged exotropia

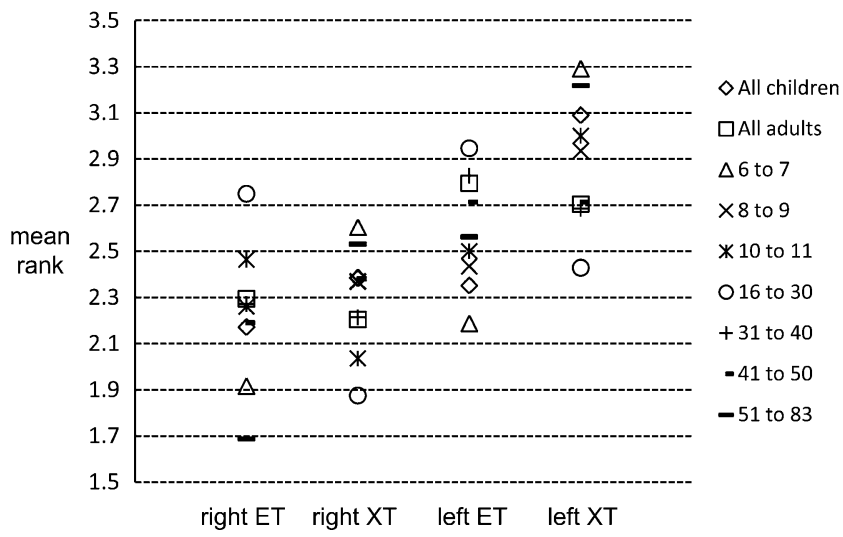

Fig. 2 Ranking of strabismus (from $1=$ most disturbing to 4 = least disturbing) for different categories of ages. $E T=$ esotropia, $X T=$ exotropia worse than esotropia. A direct comparison of these studies is difficult, since differences exist in the cultural background and profession of the interviewed subjects.

Our results also showed that in children, as in adults, a squint of the right eye is perceived as more disturbing than one of the left one. Additionally, in the perception of children, esotropia ranks worse than exotropia, thereby confirming the tendency found by Paysse et al. [12] in older children. This is contrary to the findings of Johns et al. [6], who were not able to find that children are influenced by the direction of the squint. However, since they also used smaller squint angles and paired different children together rather than showing the same child with different conditions side by side, the power might have been too small to detect significant differences. Interestingly, Uretmen et al. [15] found that elementary school teachers also rated esotropic children worse than exotropic for the two characteristics hard work and happiness, as well as concerning their ability to learn.

Why do children and adults rate a squint in the right eye significantly worse than one in the left? An explanation could be that the left half-face (as seen by the exploring subject) matters more. Often a face can be fully explored by using only two saccades. The first fixation is just to the left of the center of the nose and the second at the center of the nose [5]. This phenomenon is consistent with studies showing that the left half-face (as seen by the exploring subject) is more informative because of direct processing by the right hemisphere [14]. Possibly, this bias towards the left hemifield in face recognition can also partly be explained by the fact that Roman script is written from left to right, which influences the perception of our subjects [4]. If this finding can be confirmed by others, squinting patients able to alternate should be advised to look with their right eye.

Ninety-four percent of the interviewed adults would correct all forms of strabismus with a surgical intervention, and think that surgery should be covered by compulsory health insurance for everybody. Five percent think it should be 
covered only for children, and only $1 \%$ think it should not be covered at all. Sixty-nine percent of respondents found that strabismus surgery is not only cosmetic, and only $18 \%$ think that it is solely a cosmetic procedure. Adults fear that children with a squint could be made fun of by other children, could be less accepted by peers, looked at strangely, or have problems with their eyesight. Our results show that the opinion of adults is in good agreement with what is scientifically known about the psychosocial impact of strabismus, and that strabismus surgery is reconstructive and not cosmetic [1, 7, 13, 16].

This study has the following limitations. First, the photographs show static eyes and large-angle squints were used. Therefore, it cannot be excluded that in reality exotropia and esotropia might be perceived differently. Also, photographs with smaller squint angles might be judged differently. Second, the sample included people mainly living in the German part of Switzerland. Extrapolation to other countries or even cultures should only be done with caution.

In conclusion, adults and children rated a squinting right eye worse than a left one. Children perceived esotropia to be more disturbing than exotropia, while in adults no difference was found. Neither age, nor gender, nor the fact that the respondents have friends or family members with a squint, had an influence on this ranking. Almost all adults would correct all forms of strabismus, and think that surgery should be covered by compulsory health insurance.

\section{References}

1. Beauchamp GR, Felius J, Stager DR, Beauchamp CL (2005) The utility of strabismus in adults. Trans Am Ophthalmol Soc 103:164-171
2. Coats DK, Paysse EA, Towler AJ, Dipboye RL (2000) Impact of large angle horizontal strabismus on ability to obtain employment. Ophthalmology 107:402-405

3. Goff MJ, Suhr AW, Ward JA, Croley JK, O'Hara MA (2006) Effect of adult strabismus on ratings of official U.S. Army photographs. J AAPOS 10:400-403

4. Heath RL, Rouhana A, Ghanem DA (2005) Asymmetric bias in perception of facial affect among Roman and Arabic script readers. Laterality 10:51-64

5. Hsiao JH, Cottrell G (2008) Two fixations suffice in face recognition. Psychol Sci 19:998-1006

6. Johns HA, Manny RE, Fern KD, Hu YS (2005) The effect of strabismus on a young child's selection of a playmate. Ophthalmic Physiol Opt 25:400-407

7. Menon V, Saha J, Tandon R, Mehta M, Khokhar S (2002) Study of the psychosocial aspects of strabismus. J Pediatr Ophthalmol Strabismus 39:203-208

8. Mojon-Azzi SM, Mojon DS (2007) Opinion of headhunters about the ability of strabismic subjects to obtain employment. Ophthalmologica 221:430-433

9. Mojon-Azzi SM, Mojon DS (2009) Strabismus and employment: the opinion of headhunters. Acta Ophthalmol 87:784-788

10. Mojon-Azzi SM, Potnik W, Mojon DS (2008) Opinions of dating agents about strabismic subjects' ability to find a partner. Br J Ophthalmol 92:765-769

11. Olitsky SE, Sudesh S, Graziano A, Hamblen J, Brooks SE, Shaha SH (1999) The negative psychosocial impact of strabismus in adults. J AAPOS 3:209-211

12. Paysse EA, Steele EA, McCreery KM, Wilhelmus KR, Coats DK (2001) Age of the emergence of negative attitudes toward strabismus. J AAPOS 5:361-366

13. Satterfield D, Keltner JL, Morrison TL (1993) Psychosocial aspects of strabismus study. Arch Ophthalmol 111:1100-1105

14. Shillcock R, Ellison TM, Monaghan P (2000) Eye-fixation behavior, lexical storage, and visual word recognition in a split processing model. Psychol Rev 107:824-851

15. Uretmen O, Egrilmez S, Kose S, Pamukcu K, Akkin C, Palamar M (2003) Negative social bias against children with strabismus. Acta Ophthalmol Scand 81:138-142

16. Wagner RS (2002) Other benefits of strabismus surgery. J Pediatr Ophthalmol Strabismus 39:197 